OPEN ACCESS

Edited by:

Bartosz Adamczyk,

Natural Resources Institute Finland

(Luke), Finland

Reviewed by:

Rubén Retuerto,

University of Santiago

de Compostela, Spain

Bruce Kimball,

Animal and Plant Health Inspection

Service (USDA), United States

${ }^{*}$ Correspondence:

Sari Stark

sari.stark@ulapland.fi

Specialty section

This article was submitted to

Functional Plant Ecology,

a section of the journal

Frontiers in Plant Science

Received: 08 October 2018 Accepted: 10 December 2018

Published: 21 December 2018

Citation:

Stark S and Martz F (2018) Gender Dimorphism Does Not Affect Secondary Compound Composition in Juniperus communis After Shoot Cutting in Northern Boreal Forests.

Front. Plant Sci. 9:1910. doi: 10.3389/fpls.2018.01910

\section{Gender Dimorphism Does Not Affect Secondary Compound Composition in Juniperus communis After Shoot Cutting in Northern Boreal Forests}

\author{
Sari Stark ${ }^{1,2 *}$ and Françoise Martz ${ }^{2}$ \\ ${ }^{1}$ Arctic Centre, University of Lapland, Rovaniemi, Finland, ${ }^{2}$ Production System Unit, Natural Resources Institute Finland \\ (Luke), Rovaniemi, Finland
}

Due to a difference in plant resource allocation to reproduction, the males of dioecious plants may be more growth-orientated, whereas females may allocate more resources for synthesizing secondary compounds. This mechanism is considered to cause gender-specific differences in the plant responses to the loss of plant biomass. Here, we tested gender dimorphism in the responses of common juniper (Juniperus communis) to shoot cutting in four juniper populations located in northern boreal forests in Finland. We collected shoots from uncut junipers and from junipers subjected to shoot cutting in the previous year, and analyzed them for their shoot growth as well as phenolic and terpenoid concentrations. There were no differences in foliar phenolic or terpenoid concentrations between the males and the females. Shoot cutting increased phenolic but not terpenoid concentrations, similarly, in both males and females. Our study reveals that the nature of gender dimorphism may differ among species and locations, which should be considered in theories on plant gender dimorphism. Given the similar phenolic and terpene concentrations in both genders, the different sexes in the northern juniper populations might experience equal levels of herbivory. This lack of gender dimorphism in biotic interactions could result from the high need of plant secondary metabolites (PSM) against abiotic stresses, which is typical for juniper at high latitudes.

Keywords: Juniperus communis, phenolics, terpenoids, compensatory growth, secondary metabolism, boreal forest

\section{INTRODUCTION}

It has long been considered that in dioecious plant species, the growth rates and chemical defenses may differ between female and male individuals (Ågren et al., 1999; Cornelissen and Stiling, 2005; Avila-Sakar and Romanow, 2012). The gender-specific differences in plant carbon allocation likely result from a higher resource investment to reproduction in females, which may lead to a lower growth rate and higher concentrations of plant secondary metabolites (PSM) in females compared with males. Gender dimorphism is also suggested to influence plant responses to the loss of biomass in response to herbivory (Cornelissen and Stiling, 2005). In slow-growing woody plants, the loss of biomass often induces an increase in PSMs, which constitutes an important part of the plant resistance against invertebrate herbivory (Haukioja and Koricheva, 2000) and 
mammalian browsing (Bryant et al., 1991, 2014). Whether this is a defense reaction or an indirect result of environmental constraints that regulate the trade-off between plant growth and synthesis of secondary phenolic compounds has remained unclear (Tuomi et al., 1990; Jones and Hartley, 1999; Mattson et al., 2005). The capacity of plants to compensate for the lost biomass through increased growth rates (i.e., plant compensatory growth) constitutes another important means of plant tolerance to herbivory (Lehtilä, 2000; Tiffin, 2000; Peinetti et al., 2001; Cromsigt and Kuijper, 2011). Owing to gender dimorphism, males may more commonly respond to the loss of plant biomass by compensatory growth, whereas females respond by increasing plant secondary compounds (Cornelissen and Stiling, 2005).

The secondary compounds in plants exhibit a diverse spectrum of biological functions, and several factors regulate their synthesis (Koricheva et al., 1998; Stamp, 2003; Theis and Lerdau, 2003). Plant secondary metabolites can roughly be gathered in three classes of chemical compounds, namely alkaloids, phenolic compounds and terpenes, with $1000 \mathrm{~s}$ of compounds in each class (Chomel et al., 2016). PSMs have important roles in plant development, plant-plant and plant-microbe/insect/herbivore interactions; they also govern the mechanisms of allelopathy, influencing intraand interspecific competition between plants. Despite wellestablished importance of gender dimorphism, the majority of studies investigating the effects of environmental stresses on PSMs has focused on plant phenolics (e.g., Cornelissen and Stiling, 2005) while less is known about gender dimorphism of terpenoids. For understanding the ecological consequences of gender-specific differences on plant growth and survival, more studies are needed on the role of sexual dimorphism that would consider the multiple functions of the different classes of PSMs.

Common juniper (Juniperus communis) of the Cupressaceae family is an evergreen dioecious gymnosperm shrub that has one of the widest global distributions of any gymnosperm (Thomas et al., 2007). In Europe, the distribution of juniper ranges from the Mediterranean to the Arctic and within each area, is found in a very wide range of habitats, such as old pastures, forests, and peatlands. Juniper foliage is rich in secondary substances, particularly terpenoids and phenolics (Martz et al., 2009). Previous studies have demonstrated strong gender dimorphism in juniper. For example, juniper populations may be biased toward males, because females have higher mortality rates in resource-limited conditions (Ortiz et al., 2002). The males of Juniperus thurifera start flowering younger (Gauquelin et al., 2002). Different juniper genders also exhibit differing physiological responses to shading from neighboring plants (Verdú et al., 2004). Some studies on junipers, however, have not found gender-specific differences in growth or survival (Marion and Houle, 1996; Ortiz et al., 2002), or these differences have been highly site-specific (DeSoto et al., 2016). Northern boreal juniper populations provide an excellent opportunity to investigate gender dimorphism in plants, because these populations grow in stressful environments and have high concentrations of both phenolics and terpenes in their biomass (Martz et al., 2009).

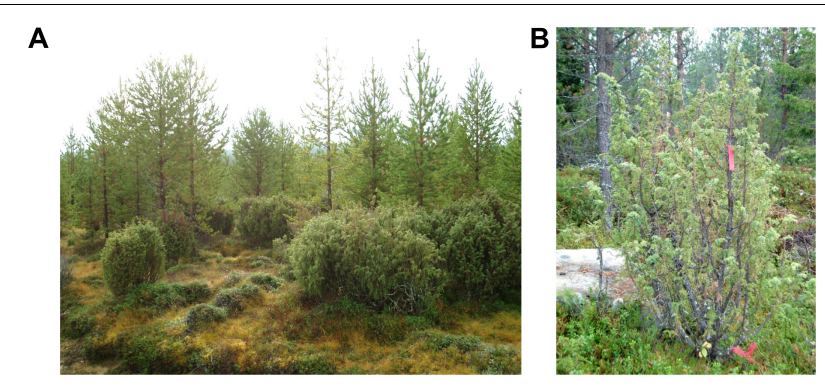

FIGURE 1 | Junipers in northern boreal forest sites (A: Savukoski, B: Salla) in Finland.

Here, we analyzed gender dimorphism in juniper by analysing the secondary compounds and responses to shoot cutting in northern boreal forests in Finland. In northern boreal forest, junipers commonly form polycormic tall shrubs instead of trees (Figure 1). We assumed that if there are differences in the reproductive effort between the genders, male and female individuals should differ in growth rates and the concentrations of PSM as well as in their responses to a loss of shoot biomass. We predicted that (1) concentrations of secondary metabolites should be higher whereas growth rates lower in females than males. As woody plants respond to biomass loss both by compensatory growth and production of secondary metabolites, we further predicted that (2) shoot cutting should induce a stronger increase in the concentrations of PSMs in females than males, whereas the compensatory growth after biomass loss should be higher in males than females.

\section{MATERIALS AND METHODS}

\section{Study Sites and Selecting Junipers for Study}

For our investigation, we selected four sites in northern Finland with dense juniper population in a uniform area (Table 1). All sites are located in the northern boreal vegetation zone and can be classified as mid-successional boreal forests with Scots pine (Pinus sylvestris) as the dominant tree species. We compared the role of gender and the loss of biomass in these populations, because the local communities had used these sites for shoot collection for natural products. Common juniper extract is used in some pharmaceutical and technical preparations, cosmetic products, and as a food additive (Mäkitalo et al., 2006; Stark et al., 2010). As part of an applied research project to investigate the recovery rate of junipers from shoot gathering and for creating recommendations for sustainable gathering (see Stark et al., 2010), we searched for several sites with a history of commercial shoot gathering during years 2002-2004. In each site, we randomly chose male and female junipers in a collected area and in an adjacent uncollected area (i.e., ranging from a few $100 \mathrm{~m}$ to $5 \mathrm{~km}$; Table 1). Individuals with shoot cut in $2004-$ generally implemented by cutting with knives or by striping were identified in collaboration with collectors. In the sites used 
TABLE 1 | Study sites and their geographical location.

\begin{tabular}{lccc}
\hline Site \# & Site name & Coordinates & $\begin{array}{c}\text { Total number } \\
\text { of samples }\end{array}$ \\
\hline S1 & Rovaniemi & $66^{\circ} 30^{\prime} \mathrm{N}, 25^{\circ} 44^{\prime} \mathrm{E}$ & 40 \\
S2 & Keminmaa & $65^{\circ} 48^{\prime} \mathrm{N}, 24^{\circ} 32^{\prime} \mathrm{E}$ & 24 \\
S3 & Salla & $66^{\circ} 50^{\prime} \mathrm{N}, 28^{\circ} 40^{\prime} \mathrm{E}$ & 32 \\
S4 & Savukoski & $67^{\circ} 17^{\prime} \mathrm{N}, 28^{\circ} 09^{\prime} \mathrm{E}$ & 32 \\
\hline
\end{tabular}

The total number of samples includes all individuals (males and females in the uncut and cut areas within each site).

for shoot gathering, the collectors generally gather shoots from each juniper as they go through the area. Consequently, the different juniper individuals are subjected to shoot cutting in a randomized way that does not depend on juniper characteristics such as size or growth rate. When selecting juniper individuals for our study, we also ensured that each of them was cut by a visual identification of cutting marks.

\section{Sampling}

The chemical quality of needles and shoot growth rates were collected and analyzed in July 2005, 1 year after the previous shoot cutting. In the field, morphological data were recorded on the selected junipers $[N=6$ per treatment in Keminmaa (S1), $N=10$ in Rovaniemi (S2), $N=8$ in Salla (S3), and Savukoski (S4)]. For each shrub, we recorded: (1) height of tree, (2) diameter of the crown of the shrub from two directions, which, together with height, was later used for calculating an approximation of juniper shrub volume, (3) dry weight of the current year shoots, (4) needle coverage (\%), (5) percentage of top dead shoots. We collected a sample of 15-40 (depending on the size of the juniper) current-year shoots from each individual. Current-year shoots (including stem) were stored in paper bags and transported to the laboratory within 1-2 days where they were immediately air dried $\left(60^{\circ} \mathrm{C} 1\right.$ day), milled and stored in sealed plastic bag at $+4^{\circ} \mathrm{C}$ in the dark until analysis. We analyzed the mean fresh and dry weight (drying at $60^{\circ} \mathrm{C}$ for $48 \mathrm{~h}$ ) of the shoot samples, indicative of their growth rate, by calculating the number of shoots and analysing the total weight of the dried samples.

\section{Chemical Analyses}

PSM were extracted from dry powder and analyzed as previously described (Martz et al., 2009). Briefly a one-step extraction protocol was developed to extract terpenoid in hexane and soluble phenolics in methanol 75\%. Milled juniper needles $(0.5 \mathrm{~g})$ were extracted with $4 \mathrm{ml}$ of methanol: $\mathrm{H}_{2} \mathrm{O}(3: 1, \mathrm{v} / \mathrm{v})+4 \mathrm{ml}$ $\mathrm{n}$-hexane by shaking $2 \mathrm{~h}$ in the dark at room temperature. Isoborneol $(200 \mu \mathrm{g})$ was added before shaking as internal standard for terpenoids.

After centrifugation, the upper organic fraction containing terpenoids was removed, concentrated and analyzed by gas chromatography with a HP-5 $(30 \mathrm{~m} \times 320 \mu \mathrm{m} \times 0.25 \mu \mathrm{m})$ column (Agilent Technologies, Santa Clara, CA, United States) using the following conditions: injector $200^{\circ} \mathrm{C}$, flame ionization detector $280^{\circ} \mathrm{C}$, helium as carrier gas $(1 \mathrm{ml} / \mathrm{min})$ and the following temperature programme: $50-80^{\circ} \mathrm{C}$ at $15^{\circ} \mathrm{C} / \mathrm{min}$, $80-100^{\circ} \mathrm{C}$ at $3^{\circ} \mathrm{C} / \mathrm{min}, 100-160^{\circ} \mathrm{C}$ at $10^{\circ} \mathrm{C} / \mathrm{min}, 160-200^{\circ} \mathrm{C}$ at $3^{\circ} \mathrm{C} / \mathrm{min}, 200-250^{\circ} \mathrm{C}$ at $15^{\circ} \mathrm{C} / \mathrm{min}$. Terpenoids were identified and quantified as described previously (Martz et al., 2009). The internal standard isoborneol was used for calculation of the efficiency of recovery of each sample during the whole extraction process. Limonene and $\alpha$-pinene were used to draw calibration curves for all monoterpenes (average curve used) and $\beta$-caryophyllene was used, similarly, for all sesquiterpenoids. Only monoterpenoids and sesquiterpenoids were quantified in this study, and their sum labeled as "terpenoid content."

Soluble phenolics present in the lower aqueous fraction were analyzed by HPLC (Waters, Milford, MA, United States) with a Spherisorb ODS II column $(4.6 \times 250 \mathrm{~mm}$, particle size $5 \mu \mathrm{m}$ ) column (Waters, Milford, MA, United States) using a binary solvent system (solvent A: $1 \%$ ammonium formiate, $10 \%$ formic acid in water; solvent B: $1 \%$ ammonium formiate, $10 \%$ formic acid in methanol). The elution programme was as follow: $0-5 \mathrm{~min}: 0 \% \mathrm{~B}, 5-45 \mathrm{~min}: 0-100 \% \mathrm{~B}, 45-86 \mathrm{~min}$ : $100 \% \mathrm{~B}$; $86-90 \mathrm{~min}: 100-0 \% \mathrm{~B}, 90-120 \mathrm{~min}: 0 \% \mathrm{~B}$, at $35^{\circ} \mathrm{C}$ and at $1 \mathrm{ml} / \mathrm{min}$. Detection and quantification were made at $280 \mathrm{~nm}$ using a UV/visible diode-array detector (Waters PDA 996). The following compounds were used to draw calibration curves for quantification: catechin (for proanthocyanidins and unknown compounds), rutin (for all flavonols) and apigetrin (for all flavones).

\section{Calculation and Statistics}

The volume of the individual juniper plants was computed using the height and the averaged width ( 2 values). The raw data have been used in Figures 1, 2; values are the mean of the four sites $\pm \mathrm{SE}$ of the mean. For statistical analysis, data were transformed when required to meet the assumption of normality. Log10 transformation was applied to shoot biomass, volume of the shrub, total phenolics, \% of monoterpenes, Grp3, Grp4, Grp5, $\mathrm{U} 1, \alpha$-pinene. Square root transformation was used for total terpenoids and the \% of U2. The experiment followed a blockdesign, with site used as blocks. The Linear Mixed Model was used with gender, cutting and their interaction as fixed factors and site as a random factor. Variance component was used as a covariance structure. All statistical testing was conducted with the IBM SPSS Statistics Software (Version 25.0, SPSS Inc., Chicago, IL, United States).

\section{RESULTS}

\section{Composition of Phenolics and Terpenoids in the Common Juniper Shoots}

The chemical composition of juniper shoots was similar to that previously reported from samples in Finland (Martz et al., 2009). Thirty-six peaks were identified by HPLC analysis. According to their UV spectra and comparison with authentic standards, the peaks were gathered into seven groups. In order of decreasing abundance, we identified: proanthocyanidins (PAs) (including catechin; Group 1), flavones (mainly apigenin 

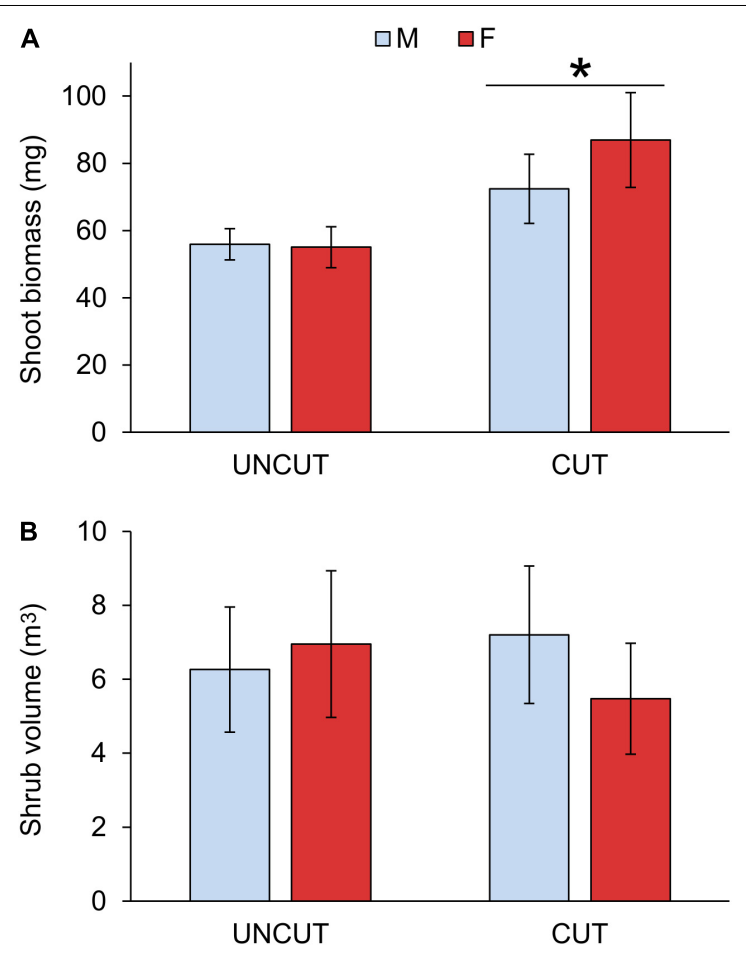

FIGURE 2 | Effect of cutting and gender on shoot biomass (A) and volume of the shrub (B). UNCUT = uncut junipers, CUT = junipers subjected to shoot cutting in the previous year. Values are mean \pm S.E. $(n=4$ sites). A star indicates statistically significant cutting effect at $p=0.001$.

derivatives; Group 2), flavonols (including quercetin derivatives; Group 3), and unidentified compounds ("others," Group 4). Although unidentified as well, a few compounds with similar spectra were detected and thus were not included in group 4: group 5 (two compounds with $\lambda \max$ of 284 and $311 \mathrm{~nm}$ ) and group 6 (two compounds with $\lambda \max$ of 280,296 , and 305 or 277,305 , and $328 \mathrm{~nm}$ ). In addition, two unidentified individual compounds, which were not included in group 4 because of their significant abundance, were detected as follows: U1 $(\lambda \max =266 \mathrm{~nm}$ with a shoulder at $300 \mathrm{~nm}$, possibly a neolignan) and U2 $(\lambda \max =273 \mathrm{~nm})$ (Martz et al., 2009; Table 2 and Supplementary Table S1). The terpenoid composition appeared much more variable and the most abundant compounds were of germacrene types (B, D-ol, D) (sesquiterpenoids), $\alpha$-pinene and several unknown compounds.

\section{Effect of Cutting on Growth Rate}

A significant increase in shoot biomass of juniper shoots was measured due to previous-year cutting (Figure 2 and Table 3). In the uncut plots, male and female did not show any difference in growth. However, females tended to have a higher growth rate after cutting, although the interaction between cutting and gender was only marginally significant $(P=0.085$; Table 3 and Supplementary Table S2). Previous-year cutting did not affect the needle coverage nor the proportion of top dead shoots (Table 3). The site had no significant effect on modeling the shoot biomass, volume of the shrub, needle coverage or top dead shoots (Wald $Z$-test: $p=0.241,0.256,0.468$, and 0.857 , respectively).

\section{Effect of Cutting on PSM}

Previous-year cutting significantly increased the total phenolic content in juniper shoots in both male and female individuals (Figure 3 and Table 3 and Supplementary Table S2). The phenolic composition was as well affected by cutting with significant increases in flavonols and compounds of Group 6 as well as decreases in abundances of compounds in Groups 4 and 5 (Table 2). Flavonols represent a major group of phenolics in juniper shoots, and a detailed analysis of the individual compounds showed that 3 compounds of the four flavonols detected increased in response to cutting (Supplementary Table S1). Only hyperin, the most abundant flavonol, was not affected by cutting. Although the abundance of all flavones (Group 2) did not significantly increase in response to cutting, two specific compounds (apigenin derivative 1: $\lambda \max 272$, $332 \mathrm{~nm}$ and U31: $\lambda \max 268,335)$ were more abundant in shoots from collected junipers. Several compounds in Group 4 showed the same decreasing abundance after cutting. Two other unknown compounds (U11 in Group 5: $\lambda \max 291,316 \mathrm{~nm}$ and U27 in Group 6: $\lambda \max 277,305,328 \mathrm{~nm}$ ) were as well significantly affected due to cutting (Supplementary Table S1). Neither the terpenoid content nor its composition was affected by cutting (Tables 2, 3). The site had no significant effect on modeling the phenolic or terpenoid concentrations (Wald $Z$-test: $p=0.252$ and 0.241 , respectively).

\section{Effect of Gender Dimorphism on PSMs}

Generally only little significant difference was observed between males and females in uncut areas and response to cutting (Tables 2, 3 and Supplementary Table S2). Only one phenolic (U18: $\lambda \max 280,367 \mathrm{~nm}$, in Group 4) was marginally more abundant in males than females shoots (Supplementary Table S1). A gender-specific difference was observed in the abundance of germacrenes with significantly higher abundance in females compared to males, especially in uncut areas (Table 3).

\section{DISCUSSION}

Studies on dioecious plants have documented gender-related differences in growth rates and concentrations of secondary metabolites with higher growth but lower PSM concentrations in males compared with females (e.g., Ågren et al., 1999; Cornelissen and Stiling, 2005). Consequently, in dioecious plant species, the intensity of herbivory may be biased toward males (Cornelissen and Stiling, 2005). Studies have found exceptions to these generalizations (Avila-Sakar and Romanow, 2012), and among the species belonging to the dioecious Juniperus genus, previous evidence on gender dimorphism has also been mixed. Contrasting the generalization, Massei et al. (2006) found higher concentrations of terpenes and phenolics in male than female individuals in Mediterranean J. oxycedrus macrocarpa, and McGowan et al. (2004) that the females of prostrate juniper J. communis ssp. nana in northern Scotland 
TABLE 2 | Phenolic and terpenoid composition in juniper shoots and statistical significance of cutting, gender, or cutting by gender interaction effects calculated using the Mixed Linear Model.

\begin{tabular}{|c|c|c|c|c|c|c|c|}
\hline \multirow[t]{3}{*}{ Compounds } & \multicolumn{4}{|c|}{ Concentration (\%) } & \multicolumn{3}{|c|}{$F$-value } \\
\hline & \multicolumn{2}{|c|}{ Uncut } & \multicolumn{2}{|c|}{ Cut } & \multirow[t]{2}{*}{ Cutting } & \multirow[t]{2}{*}{ Gender } & \multirow[t]{2}{*}{ Cutting * gender } \\
\hline & M & $\mathbf{F}$ & M & $\mathbf{F}$ & & & \\
\hline \multicolumn{8}{|l|}{ Phenolics } \\
\hline PA (1) & $22.7 \pm 1.1$ & $23.2 \pm 1.3$ & $22.6 \pm 1.4$ & $23.2 \pm 1.4$ & 0.035 & 0.694 & 0.008 \\
\hline Flavones (2) & $16.7 \pm 0.7$ & $16.0 \pm 0.7$ & $17.3 \pm 0.9$ & $17.1 \pm 0.9$ & 2.306 & 0.753 & 0.272 \\
\hline Flavonols (3) & $17.9 \pm 0.8$ & $17.9 \pm 0.8$ & $19.7 \pm 1.0$ & $18.9 \pm 1.0$ & $5.988^{*} \uparrow$ & 0.365 & 1.221 \\
\hline Others (4) & $20.9 \pm 0.6$ & $20.2 \pm 0.7$ & $19.5 \pm 0.7$ & $19.5 \pm 0.6$ & $8.283^{* *} \downarrow$ & 1.181 & 1.981 \\
\hline Group 5 & $8.0 \pm 0.3$ & $8.0 \pm 0.4$ & $7.0 \pm 0.3$ & $6.9 \pm 0.3$ & $17.824^{* *} \downarrow$ & 0.072 & 0.053 \\
\hline Group 6 & $4.7 \pm 0.2$ & $4.9 \pm 0.3$ & $5.3 \pm 0.3$ & $5.3 \pm 0.6$ & $9.286^{* *} \uparrow$ & 0.571 & 0.309 \\
\hline U1 & $4.4 \pm 0.7$ & $5.3 \pm 0.8$ & $4.3 \pm 0.6$ & $4.5 \pm 0.6$ & 1.760 & 0.022 & 1.101 \\
\hline U2 & $4.7 \pm 0.3$ & $4.4 \pm 0.2$ & $4.4 \pm 0.4$ & $4.6 \pm 0.4$ & 1.056 & 1.142 & 0.307 \\
\hline \multicolumn{8}{|l|}{ Terpenoids } \\
\hline Monoterpenes & $17.5 \pm 2.1$ & $15.0 \pm 1.7$ & $13.5 \pm 1.8$ & $13.4 \pm 1.3$ & 1.619 & 0.205 & 0.627 \\
\hline Sesquiterpenes & $82.5 \pm 2.1$ & $85.0 \pm 1.7$ & $86.5 \pm 1.8$ & $86.6 \pm 1.3$ & - & - & - \\
\hline Germacrene & $31.9 \pm 2.1$ & $36.8 \pm 2.1$ & $30.6 \pm 1.8$ & $32.4 \pm 1.4$ & 3.256 & $4.227^{*} \uparrow$ & 0.823 \\
\hline$\alpha$-pinene & $10.3 \pm 1.6$ & $8.3 \pm 1.3$ & $7.8 \pm 1.3$ & $7.7 \pm 1.0$ & 0.354 & 0.509 & 0.748 \\
\hline
\end{tabular}

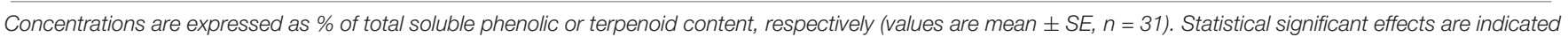
by ${ }^{* *}(p<0.01)$ or* $(p<0.05)$. An arrow indicates the direction of the change: CUT compared to UNCUT, and FEMALE compared to MALE.

were more frequently subjected to herbivory than males. No gender-specific difference in juniper growth was observed along an altitudinal gradient in Sierra Nevada despite decreasing reproductive success along this gradient (Ortiz et al., 2002). Here, except for a few individual compounds, we found no effects of gender in phenolic and terpenoid concentrations in J. communis in northern boreal forests. Although, as predicted, shoot cutting significantly increased phenolic concentrations, the level of PSMs increased, similarly, in both males and females. Further, theories on gender dimorphism state that males should be more growth-orientated than females (e.g., Ågren et al., 1999; Cornelissen and Stiling, 2005), but we found marginally $(P<0.10)$ higher growth after shoot cutting in females compared with males.

The lack of clear gender dimorphism in PSMs and growth in northern juniper populations compared with e.g., boreal deciduous trees (Nissinen et al., 2018; Ruuhola et al., 2018; Zhang et al., 2018) is noteworthy, because junipers in these systems seem to have a particularly high level of chemical defense. Along a large geographical gradient from the southern to northern boreal forests, Martz et al. (2009) found that secondary compound concentrations in the common juniper significantly increased with latitude. Interestingly, these trends were similar in both terpenoids and phenolics, although these compound groups exert largely differing ecological functions. Terpenoids may have a key role in the defense against mammalian herbivory (Mutikainen et al., 2000), and the low palatability of juniper to herbivores is commonly derived from oils found in the needles, cones and wood, dominated by monoterpenes (Thomas et al., 2007). Despite the low palatability, junipers are commonly subjected to herbivory in different habitats (Livingston, 1972; Miller et al., 1982; Fuhlendorf et al., 1997), and in the boreal forests, herbivory on juniper is dominated by shoot consumption by moose (Alces alces) during the winter. Contrasting with terpenoids, phenolics may have a higher importance in the plant protection against invertebrate herbivory (Koricheva et al., 1998), and photooxidative stress (Close and McArthur, 2002). The need for antioxidative compounds in relation to light intensity may increase in conditions of both nutrient deficiency and low temperature (Close and McArthur, 2002), which could explain why their concentrations increase with latitude (Stark et al., 2008; Martz et al., 2009, 2010). Traditional theories also suggested that greater concentrations of phenolics may result from allocation of extra photosynthesized carbon to secondary metabolites as a result of nutrient deficiency (Bryant et al., 1983; Mattson et al., 2005).

Although both phenolic and terpenoid concentrations in juniper seem to show a similar gradient with increasing latitude (Martz et al., 2009), here, we found that the responses of PSM concentrations to shoot cutting varied greatly among the different compounds and compound groups. More specifically, cutting lead to increased concentrations of soluble phenolics and a higher abundance of flavonoids (specific flavones and flavonol glycosides). As we analyzed samples 1 year after the shoot cutting, our analyses depict delayed inducible reactions that take place after a time lag from the loss of biomass (Tuomi et al., 1990). Although previous studies have indicated that delayed inducible 
TABLE 3 | Statistical significance of cutting, gender and their interaction on growth and secondary compounds in juniper shoots calculated using the Linear Mixed Model (see Materials and Methods).

\begin{tabular}{|c|c|c|c|}
\hline Variable & Fixed effect & $F$-value & $p$-value \\
\hline \multicolumn{4}{|l|}{ Growth } \\
\hline \multirow[t]{3}{*}{ Shoot biomass } & Cutting & 30.464 & $<0.001^{* *}$ \\
\hline & Gender & 0.551 & 0.460 \\
\hline & Cutting*gender & 3.015 & 0.085 \\
\hline \multirow[t]{3}{*}{ Volume } & Cutting & 0.270 & 0.605 \\
\hline & Gender & 0.192 & 0.662 \\
\hline & Cutting*gender & 0.849 & 0.359 \\
\hline \multirow[t]{3}{*}{ Needle coverage (\%) } & Cutting & 0.009 & 0.923 \\
\hline & Gender & 1.242 & 0.268 \\
\hline & Cutting*gender & 0.019 & 0.891 \\
\hline \multirow[t]{3}{*}{ Top dead shoots (\%) } & Cutting & 0.002 & 0.961 \\
\hline & Gender & 0.010 & 0.921 \\
\hline & Cutting*gender & 0.104 & 0.748 \\
\hline \multicolumn{4}{|c|}{ Secondary Compounds } \\
\hline \multirow[t]{3}{*}{ Total phenolics } & Cutting & 14.838 & $<0.001^{* *}$ \\
\hline & Gender & 0.849 & 0.359 \\
\hline & Cutting*gender & 0.029 & 0.865 \\
\hline \multirow[t]{3}{*}{ Terpenoids } & Cutting & 2.492 & 0.117 \\
\hline & Gender & 0.653 & 0.421 \\
\hline & Cutting*gender & 0.937 & 0.335 \\
\hline
\end{tabular}

Statistical significant effects are indicated by ** $(p<0.01)$ or * $(p<0.05)$.

reactions in conifers is relatively uncommon when compared with the deciduous trees (Nykänen and Koricheva, 2004), increasing phenolic concentrations in response to shoot cutting agree with previous findings on e.g., Pinus species (Honkanen et al., 1999; Roitto et al., 2008). Flavonols in juniper are mainly quercetin derivatives that exert strong antioxidant activity due to their chemical features (Rice-Evans et al., 1997); thus, shoot cutting led to higher abundances of compounds with a high antioxidant capacities that are more efficient in relation to the carbon cost to their synthesis (sensu Close and McArthur, 2002).

Contrasting with phenolics, we found no overall shoot cutting effect on terpenoids. In line with our investigation, the previous study by Honkanen et al. (1999) also found increasing phenolic concentrations in response to defoliation in boreal coniferous tree Pinus sylvestris L. but no effects on terpenoids, despite they are considered the main class of antiherbivore defensive compounds. Contrasting with this idea, a meta-analysis by Nykänen and Koricheva (2004) concluded that the damage in woody plants quite commonly reduces the concentrations of terpenes. This may be true also in the case of juniper, as reduced yields of essential oils in junipers after a severe browsing damage have previously been found (Markó et al., 2008). Condensed tannins and flavonoids, among many other phenolic compounds are derived from phenylalanine via the phenylpropanoid pathway (Vogt, 2011) and terpenoids are synthesized via acetyl-CoA, pyruvate and glyceraldehyde3-phosphate in parallel cytosolic of plastid metabolic pathways (Singh and Sharma, 2015). This shows that disturbance of the
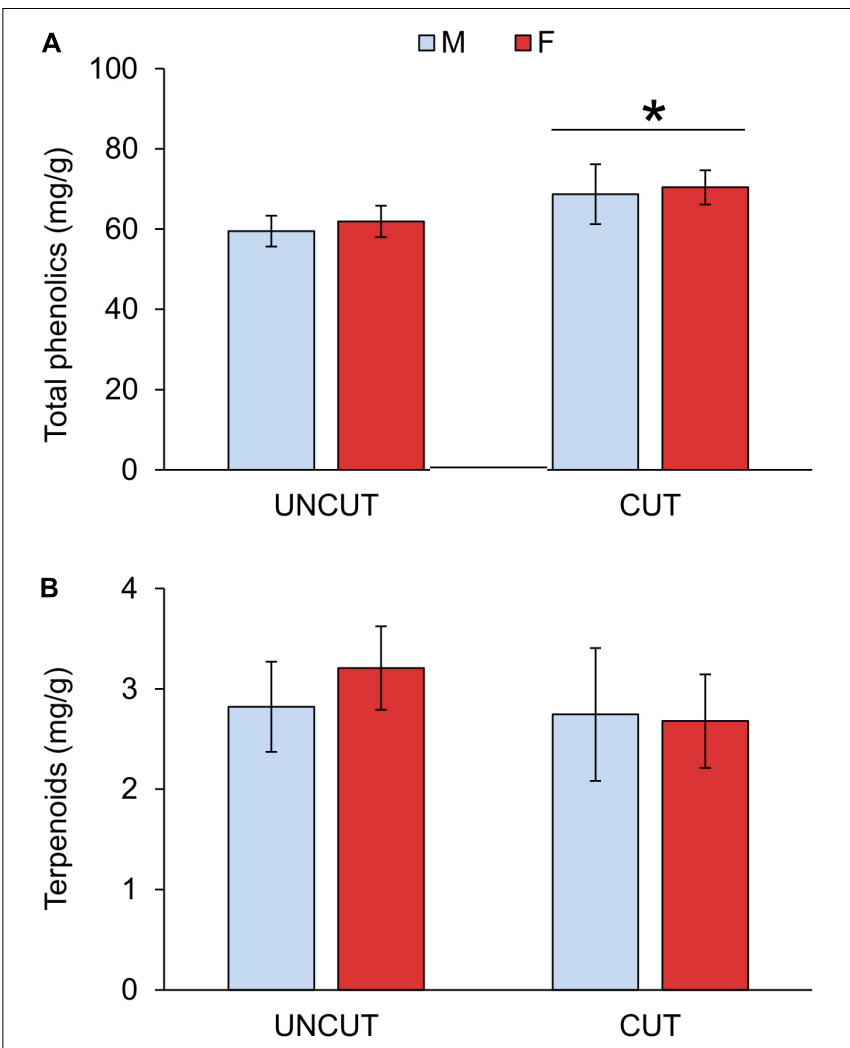

FIGURE 3 | Effect of cutting and gender on total soluble phenolics (A) and terpenoids (B) concentrations in juniper shoots. UNCUT = uncut junipers, CUT = junipers subjected to shoot cutting in the previous year. Values are mean \pm S.E. ( $n=4$ sites). A star indicates statistically significant cutting effect at $p=0.01$.

general carbon metabolism due to, for example biotic/abiotic stress or compensatory growth will have consequences on the PSM content.

Although the mechanisms underlying our findings remain uncertain, our study adds to previous evidence showing unclear or ambiguous effects of gender on growth, secondary compound concentrations and reproduction in Juniperus species (e.g., Marion and Houle, 1996; Ortiz et al., 2002; Verdú et al., 2004; Massei et al., 2006; DeSoto et al., 2016). For example, aged juniper populations are male-biased, but this bias does not seem to be easily explained by the genderspecific differences in the cost of reproduction (Gauquelin et al., 2002; Ortiz et al., 2002). Earlier reviews have already concluded that there is a need to revise theories predicting how gender dimorphism affects plant performance and responses to environmental stresses (Avila-Sakar and Romanow, 2012; Vega-Frutis et al., 2013). For woody plants, the tolerance of herbivory is a major component of plant resistance, because the probability of herbivory is high due to large size and long life span. However, the recovery potential of these species could be driven by the type of herbivory they commonly experience (Haukioja and Koricheva, 2000). Noteworthy, García et al. (2001) found that frugivory at Juniperus 
communis in the Mediterranean mountains depended largely on population characteristics rather than on individual attributes. If herbivory, such as browsing by moose, is commonly centered on locations with numerous and dense juniper populations to provide large food quantity, the chemical quality of the different individuals might not exert a primary role in the food selection of herbivores. Under these conditions, the capacity for regrowth could outweigh the importance of PSMs in herbivory tolerance. Further, the lack of clear gender dimorphism in northern boreal juniper populations could also result from the high need of PSMs at high latitude to protect from abiotic stresses (Martz et al., 2009). Although herbivory might even constitute one of the driving forces behind the evolution of dioecy in plants (Bawa, 1980; Cornelissen and Stiling, 2005; Avila-Sakar and Romanow, 2012; Vega-Frutis et al., 2013), studies on juniper populations have demonstrated that genderrelated differences in growth and resource storage may be a consequence of local adaptation to environmental conditions (DeSoto et al., 2016). Protection against abiotic stresses through the PSMs could have such major significance for plant success under northern conditions that it might override any genderspecific differences in the carbon allocation for synthesizing PSMs.

Ecological factors that limit plant success in each specific conditions could also explain why we detected a marginally higher capacity for compensatory growth in females despite a presumably higher resource cost for reproduction (sensu Cornelissen and Stiling, 2005). Over a large geographical gradient from the Mediterranean to the sub-Arctic vegetation zone across Europe, García et al. (2000) concluded that the juniper population viability in the north may in fact be under less pressure compared with juniper populations at mid-latitudes, because these populations are free from seed predation. Experimental evidence on dioecious plants has suggested that increasing resources may weaken gender-specific differences within plant species, and consequently, the gender-specific differences in phenolic concentrations could be pronounced under high resource limitation (Palumbo et al., 2007). Further, woody plants seem to recover from the loss of biomass better under low than high resource availability, possibly because under these conditions, plants generally grow below their potential

\section{REFERENCES}

Ågren, J., Danell, K., Elmqvist, T., et al. (1999). "Sexual dimorphism and biotic interactions," in Gender and Sexual Dimorphism in Flowering Plants, eds M. A. Geber, T. E. Dawson, and L. F. Delph (Berlin: Springer-Verlag), 217-246. doi: 10.1007/978-3-662-03908-3_8

Avila-Sakar, G., and Romanow, C. A. (2012). Divergence in defence against herbivores between males and females of dioecious plant species. Int. J. Evol. Biol. 2012:897157. doi: 10.1155/2012/897157

Bawa, K. S. (1980). Evolution of dioecy in flowering plants. Annu. Rev. Ecol. Syst. 11, 15-39. doi: 10.1146/annurev.es.11.110180. 000311

Bryant, J. P., Chapin, F. S. III., and Klein, D. R. (1983). Carbon/nutrient balance of boreal plants in relation to vertebrate herbivory. Oikos 40, 357-368. doi: $10.2307 / 3544308$ maximum growth rate (Hawkes and Sullivan, 2001). As northern conditions with low nutrient availability, low temperatures and high light likely require high defense through PSMs (Martz et al., 2009), the combination of high need for chemical defense and low pressure on reproduction (García et al., 2000) might direct gender dimorphism from gender-specific differences in defense toward the importance of compensation after the loss of biomass.

\section{AUTHOR CONTRIBUTIONS}

SS designed the experiments and performed field sampling and measurements. FM ran the laboratory analyses and conducted statistical tests. SS and FM jointly wrote the manuscript.

\section{FUNDING}

This work was supported by the European Commission, Regional Development Fund (Projects "Mette", 70025/05, 2005-2006, "Lappi luo", 2105, 533/3560-2008, 2008-2011).

\section{ACKNOWLEDGMENTS}

We are greatly indebt to the juniper collectors for the information on the shoot collection sites around Finnish Lapland. Furthermore, we sincerely thank Riitta Nielsen for helping with the juniper shoot extractions, and Aarno Niva and Tarja Posio for invaluable input in the juniper growth measurements. We acknowledge Juha Hyvönen and Pasi Rautio for their help in statistical analyses.

\section{SUPPLEMENTARY MATERIAL}

The Supplementary Material for this article can be found online at: https://www.frontiersin.org/articles/10.3389/fpls.2018.01910/ full\#supplementary-material

Bryant, J. P., Joly, K., Chapin, III, F. S., DeAngelis, D. L., and Kielland, K. (2014). Can antibrowsing defense regulate the spread of woody vegetation in arctic tundra? Ecography 37, 204-211. doi: 10.1111/j.1600-0587.2013. 00436.x

Bryant, J. P., Provenza, F. D., Pastor, J., Reichardt, P. B., Clausen, T. P., and du Toit, J. T. (1991). Interactions between woody plants and browsing mammals mediated by secondary metabolites. Annu. Rev. Ecol. Syst. 22, 431-446. doi: 10.1146/annurev.es.22.110191.002243

Chomel, M., Guittonny-Larchevêque, M., Fernandez, C., Gallet, C., DesRochers, A., Paré, D., et al. (2016). Plant secondary metabolites: a key driver of litter decomposition and soil nutrient cycling. J. Ecol. 104, 1527-1541. doi: 10.1111/1365-2745.12644

Close, D. C., and McArthur, C. (2002). Rethinking the role of many plant phenolics - protection from photodamage not herbivores? Oikos 99, 166-172. doi: 10. 1034/j.1600-0706.2002.990117.x 
Cornelissen, T., and Stiling, P. (2005). Sex-biased herbivory: a meta-analysis of the effects of gender on plant-herbivore interactions. Oikos 111, 488-500. doi: 10.1111/j.1600-0706.2005.14075.x

Cromsigt, J. P. G. M., and Kuijper, D. P. J. (2011). Revisiting the browsing lawn concept: evolutionary interactions or pruning herbivores? Perspect. Plant Ecol. Evol. Syst. 13, 207-215. doi: 10.1016/j.ppees.2011. 04.004

DeSoto, L., Olano, J. M., and Rozas, V. (2016). Secondary growth and carbohydrate storage patterns differ between sexes in Juniperus thurifera. Front. Plant Sci. 7:723. doi: $10.3389 /$ fpls. 2016.00723

Fuhlendorf, S. D., Smeins, F. E., and Taylor, C. A. (1997). Browsing and tree size influences on Ashe juniper understory. J. Range Manage. 50, 507-512. doi: $10.2307 / 4003706$

García, D., Zamora, R., Gómex, J. M., Jordano, P., and Hódar, J. A. (2000). Geographical variation in seed production, predation and abortion in Juniperus communis throughout its range in Europe. J. Ecol. 88, 436-446. doi: 10.1046/j. 1365-2745.2000.00459.x

García, D., Zamora, R., Gómez, J. M., and Hódar, J. A. (2001). Frugivory at Juniperus communis depends more on population characteristics than on individual attributes. J. Ecol. 89, 639-647. doi: 10.1046/j.1365-2745.2001. 00577.x

Gauquelin, T., Bertaudiére-Montés, V., Badri, W., and Montés, N. (2002). Sex ratio and sexual dimorphism in mountain dioecious thuriferous juniper (Juniperus thurifera L., Cupressaceae). Bot. J. Linnean Soc. 138, 237-244. doi: 10.1046/j. 1095-8339.2002.138002237.x

Haukioja, E., and Koricheva, J. (2000). Tolerance to herbivory in woody vs. herbaceous plants. Evol. Ecol. 14, 551-562. doi: 10.1023/A:101109160 6022

Hawkes, C., and Sullivan, J. J. (2001). The impact of herbivory on plants in different resource conditions: a meta-analysis. Ecology 82, 2045-2058. doi: 10.1890/00129658(2001)082[2045:TIOHOP]2.0.CO;2

Honkanen, T., Haukioja, E., and Kitunen, V. (1999). Responses of Pinus sylvestris branches to simulated herbivory are modified by tree sink/source dynamics and external resources. Funct. Ecol. 13, 126-140. doi: 10.1046/j.1365-2435.1999. 00296.x

Jones, C. G., and Hartley, S. E. (1999). A protein competition model of phenolic allocation. Oikos 86, 27-44. doi: 10.2307/3546567

Koricheva, J., Larsson, S., Haukioja, E., and Keinänen, M. (1998). Regulation of woody plant secondary metabolism by resource availability: hypothesis testing by means of meta-analysis. Oikos 83, 212-226. doi: 10.2307/354 6833

Lehtilä, K. (2000). Modelling compensatory regrowth with bud dormancy and gradual activation of buds. Evol. Ecol. 14, 315-330. doi: 10.1023/A: 1010869605855

Livingston, R. B. (1972). Influence of birds, stones and soil on the establishment of pasture juniper, Juniperus communis, and red cedar, J. virginiana, in New England pastures. Ecology 53, 1141-1147. doi: 10.2307/193 5427

Mäkitalo, I., Siivari, J., and Hannukkala, A. (2006). Luonnosta Teolliseen Tuotantoon: Kuvaus Luonnontuotealan Kehittämishankkeesta Lapissa 20002006. Jokioinen: Maa- ja elintarviketalous (MTT).

Marion, C., and Houle, G. (1996). No differential consequences of reproduction according to sex in Juniperus communis vas. depressa (Cupressaceae). Am. J. Bot. 83, 480-488. doi: 10.1002/j.1537-2197.1996.tb1 2729.x

Markó, G., Gyuricza, V., Bernáth, J., and Altbacker, V. (2008). Essential oil yield and composition reflect browsing damage of junipers. J. Chem. Ecol. 34, 1545-1552. doi: 10.1007/s10886-008-9557-5

Martz, F., Jaakola, L., Julkunen-Tiitto, R., and Stark, S. (2010). Phenolic composition and antioxidant capacity of bilberry (Vaccinium myrtillus) leaves in northern Europe following foliar development and along environmental gradients. J. Chem. Ecol. 36, 1017-1028. doi: 10.1007/s10886-0109836-9

Martz, F., Peltola, R., Fontanay, S., Duval, R., Julkunen-Tiitto, R., and Stark, S. (2009). The effect of latitude and altitude on the terpenoid and soluble phenolic composition of juniper (Juniperus communis) needles and on its antimicrobial activities in boreal forests. J. Food Agric. Chem. 57, 9575-9584. doi: 10.1021/ jf902423k
Massei, G., Watkins, R., and Hartley, S. E. (2006). Sex-related growth and secondary compounds in Juniperus oxycedrus macrocarpa. Acta Oecol. 29, 135-140. doi: 10.1016/j.actao.2005.08.004

Mattson, W. J., Julkunen-Tiitto, R., and Herms, D. A. (2005). CO2 enrichment and carbon partitioning to phenolics: do plant responses accord better with the protein competition or the growth-differentiation balance models? Oikos 111, 337-347. doi: 10.1111/j.0030-1299.2005.13634.x

McGowan, G. M., Joensalo, J., and Naylor, R. E. L. (2004). Differential grazing of female and male plants in prostate juniper (Juniperus communis L.). Bot. J. Scotland 56, 39-54. doi: 10.1080/03746600408685066

Miller, G. R., Kinnaird, J. W., and Cummings, R. P. (1982). Liability of saplings to browsing on a red deer range in the Scottish highlands. J. Appl. Ecol. 19, 941-951. doi: 10.2307/2403295

Mutikainen, P., Walls, M., Ovaska, J., Keinänen, M., Julkunen-Tiitto, R., and Vapaavuori, E. (2000). Herbivore resistance in Betula pendula: effect of fertilization, defoliation, and plant genotype. Ecology 81, 49-65. doi: 10.2307/ 177133

Nissinen, K., Virjamo, V., Mehtätalo, L., Lavola, A., Valtonen, A., Nybakken, L., et al. (2018). A seven-year study of phenolic concentrations of the dioecious Salix myrsinifolia. J. Chem. Ecol. 44, 416-430. doi: 10.1007/s10886-018-0942-4

Nykänen, H., and Koricheva, J. (2004). Damage-induced changes in woody plants and their effects on insect herbivore performance: a meta-analysis. Oikos 104, 247-268. doi: 10.1111/j.0030-1299.2004.12 768.x

Ortiz, P. L., Arista, M., and Talavera, S. (2002). Sex ratio and reproductive effort in the dioecious Juniperus communis subsp. alpina (Suter) Celak. (Cupressaceae) along an altitudinal gradient. Ann. Bot. 89, 205-211. doi: 10.1093/aob/ mcf028

Palumbo, M. J., Putz, F. E., and Talcott, S. T. (2007). Nitrogen fertilizer and gender effects on the secondary metabolism of yaupon, a caffeine-containing North American holly. Oecologia 151, 1-9. doi: 10.1007/s00442-006-0574-1

Peinetti, H. R., Menezes, R. S. C., and Cougnenour, M. B. (2001). Changes induced by elk browsing in the aboveground biomass production and distribution of willow (Salix monticola Bebb): their relationships between plant water, carbon, and nitrogen dynamics. Oecologia 127, 334-342. doi: 10.1007/s004420000593

Rice-Evans, C. A., Miller, N. J., and Paganga, G. (1997). Antioxidant properties of phenolic compounds. Trends Plant Sci. 2, 152-159. doi: 10.1016/S13601385(97)01018-2

Roitto, M., Rautio, P., Markkola, A. M., Julkunen-Tiitto, R., Varama, M., Saravesi, K., et al. (2008). Induced accumulation of phenolics and sawfly performance in Scots pine in response to previous defoliation. Tree Physiol. 29, 207-216. doi: 10.1093/treephys/tpn017

Ruuhola, T., Nybakken, L., Randriamanana, T., Lavola, A., and JulkunenTiitto, R. (2018). Effects of long-term UV-exposure and plant sex on the leaf phenoloxidase activities and phenolic concentrations of Salix myrsinifolia (Salisb.). Plant Physiol. Biochem. 126, 55-62. doi: 10.1016/j.plaphy.2018.02.025

Singh, B., and Sharma, R. A. (2015). Plant terpenes: defense responses, phylogenetic analysis, regulation and clinical applications. 3 Biotech 5, 129-151. doi: 10.1007/ s13205-014-0220-2

Stamp, N. (2003). Out of the quagmire of plant defence hypotheses. Q. Rev. Biol. 78, 23-55. doi: 10.1086/367580

Stark, S., Julkunen-Tiitto, R., Holappa, E., Mikkola, K., and Nikula, A. (2008). Concentrations of foliar quercetin in natural populations of white birch (Betula pubescens) increase with latitude. J. Chem. Ecol. 34, 1382-1391. doi: 10.1007/ s10886-008-9554-8

Stark, S., Niva, A., Martz, F., and Vuorela, E. (2010). Sustainable Gathering of Juniper and Bilberry Shoots for Natural Product Industry (In Finnish, English abstract). Jokioinen: MTT Raportti 3.

Theis, N., and Lerdau, M. (2003). The evolution of function in plant secondary metabolites. Int. J. Plant Sci. 163(3 Suppl.), S93-S102. doi: 10.1086/374190

Thomas, P. A., El-Barghathi, M., and Polwart, A. (2007). Biological flora of the british isles: Juniperus communis L. J. Ecol. 95, 1404-1440. doi: 10.1016/j.jep. 2017.03.039

Tiffin, P. (2000). Mechanisms of tolerance to herbivory damage: what do we know? Evol.y Ecol. 14, 523-536. doi: 10.1023/A:1010881317261

Tuomi, J., Niemelä, P., and Siren, S. (1990). The panglossian paradigm and delayed inducible accumulation of foliar phenolics in mountain birch. Oikos 59, 399-410. doi: 10.2307/3545152 
Vega-Frutis, R., Munguía-Rosas, M. A., Varga, S., and Kytöviita, M. M. (2013). Sexspecific patterns of antagonistic and mutualistic biotic interactions in dioecious and gynodioecious plants. Perspect. Plant Ecol. Evol. Syst. 15, 45-55. doi: 10. 1016/j.ppees.2012.10.004

Verdú, M., Villar-Salvador, P., and García-Fayos, P. (2004). Gender effects on the post-facilitation performance of two dioecious juniper species. Funct. Ecol. 18, 87-93. doi: 10.1111/j.1365-2435.2004.00816.x

Vogt, T. (2011). Phenylpropanoid biosynthesis. Molecul. Plant 3, 2-20. doi: 10. 1093/mp/ssp106

Zhang, Y., Virjamo, V., Sobuj, N., Du, W., Yin, Y., Nybakken, L., et al. (2018). Sexrelated responses of European aspen (Populus tremula L.) to combined stress: $\mathrm{TiO} 2$ nanoparticles, elevated temperature and $\mathrm{CO} 2$ concentration. J. Hazard Mater. 352, 130-138. doi: 10.1016/j.jhazmat.2018.03.031
Conflict of Interest Statement: The authors declare that the research was conducted in the absence of any commercial or financial relationships that could be construed as a potential conflict of interest.

The handling Editor declared a shared affiliation, though no other collaboration, with one of the authors FM at the time of review.

Copyright (c) 2018 Stark and Martz. This is an open-access article distributed under the terms of the Creative Commons Attribution License (CC BY). The use, distribution or reproduction in other forums is permitted, provided the original author(s) and the copyright owner(s) are credited and that the original publication in this journal is cited, in accordance with accepted academic practice. No use, distribution or reproduction is permitted which does not comply with these terms. 